\title{
Politika gjuhësore në përcaktimin e standardit të shqipes në Kongresin e Drejtshkrimit, 1972, sipas Janet Byron dhe Arshi Pipës
}

Esma Allmuça

Përcaktimi i standardit të një gjuhe, nuk është një akt i menjëhershëm, por është po ashtu një proces, që në kohë e vende të ndryshme, ka patur veçori të ndryshme. Sa i takon gjuhës shqipe, Kongresi i Drejtshkrimit, më 1972, i dha zgjidhje përfundimtare procesit të standardizimit duke realizuar po ashtu dhe produktet apo materialet kodifikuese, përgjatë dhjetëvjeçarit 1970-1980. Në punimin tonë do të përpiqemi të vendosim në dukje pikat e përbashkëta të argumenteve që sjellin autorët J. Byron dhe A. Pipa, në monografitë e tyre, sa i takon debatit të ndikimit politik në përcaktimin e standardit të gjuhës shqipe. Përballë tyre, si kundërargument, vendoset mendimi i gjuhëtarit A. Kostallari. Përzgjedhja e një varieteti, që do të jetë bazë për standardin, nuk përbën ndonjë rast unik për shqipen, pasi kjo ka ndodhur dhe me gjuhët e tjera të botës ku është përzgjedhur një e folme e caktuar. Megjithatë, me të drejtë, sikurse bëjnë dhe këta studiues, mund të lindë debati, pse pikërisht njëri dialekt e jo tjetri edhe pse gjuhëtarët e viteve 70-80 këmbëngulin në idenë se standardi është përftuar nga bashkëveprimi i të dy dialekteve të shqipes.

Gjuhëtarët, sidomos ata me fokus në disiplinën e sociolinguistikës, ndër to përmendim gjuhëtarin Haugen, mendojnë se ekziston një model i krijimit të një gjuhe standarde që kalon përgjithësisht nëpër këto katër faza: 1. Përzgjedhja (zgjedhja e varietit ose e kodit që do të zhvillohet); 2. Kodifikimi; 3. Përpunimi; 4. Pranimi. ${ }^{1}$ Në fazën e parë përzgjidhet një varietet për t'u vendosur në

1 Holmes, Janet; Hyrje në Sociolinguistikë, Botime "Pegi", Tiranë, 2015, f. 123. 


\section{Albanon}

\section{Revistë kulturore}

bazë të standardit. Zakonisht përzgjidhet dhe promovohet një varietet me prestigj. Shumë module sociolinguistike theksojnë faktin se përzgjedhja e një varieteti lidhet ngushtë dhe me arsyet politike apo kulturore, e madje, e konsiderojnë standardizimin dhe një proces ideologjik, pasi mbështetet nga pjesa më e pushtetshme e shoqërisë. Duke qenë se në përgjithësi për çdo gjuhë kjo çështje ngjall debat, sigurisht që nuk do të mënjanohej edhe gjuha shqipe nga ky fenomen, sidomos, duke patur parasysh rrethanat politike në të cilën gjendej Shqipëria në kohën kur u realizua procesi i standardizimit të shqipes.

Konceptit të politikës gjuhësore, më së shumti, i përgjigjet sociolinguistika evropiane, që nuk e mënjanon rolin e pushtetit në procesin e standardizimit, se sa sociolinguistika amerikane, ku përfshihet dhe vepra e Janet Byron.

Ata nuk e bëjnë sa duhet dallimin ndërmjet vendimeve të pushtetit (politikës gjuhësore) dhe veprimeve konkrete (planifikimit gjuhësor). Ndryshe nga ata, përfaqësuesit e sociolinguistikës europianë, kam parasysh këtu, studiuesit francezë, spanjollë, gjermanë i kushtojnë më shumë vëmendje çështjes së rolit të pushtetit. ${ }^{2}$

Ky diferencim, midis konceptit të politikës gjuhësore dhe planifikimit gjuhësor, shpesh nuk kryhet, madje, identifikohen herë pas here si koncepte që kanë të njëjtën domethënie.

Gjuha si mjet që shërben për formimin e kategorive të mendimit e të ndërgjegjes së njerëzve, nga njëra anë, është kusht i domosdoshëm për krijimin e zhvillimin e kulturës, por edhe nga ana tjetër, prodhim $i$ kësaj kulture kombëtare e mjet $i$ pazëvendësueshëm për zhvillimin e ecjen përpara të çdo kombi. Ky është kuadri i përgjithshëm dhe universal prej nga buron kurdoherë edhe qëndrimi i vetëdijshëm ndaj gjuhës apo ajo që ne e kemi quajtur "politika gjuhësore", kurse gjetkë, me të njëjtën domethënie, përdorin termin "planifikim gjuhësor".

Në vijim të punimit do të përpiqemi të shohim pikërisht se si trajtohet në veprën e Janet Byron dhe të A.Pipës ky koncept i politikës gjuhësore që u zbatua në procesin e standardizimit të gjuhës shqipe. Vepra e Janet Byron "Përzgjedhje midis alternativash në standardizimin e gjuhës, rasti i shqipes", u botua më 1976, por u punua në fillim si tezë doktorate, nën udhëheqjen e sociolinguistit Fishman, që në 1973, pra fill pas mbledhjes së Kongresit te Drejtshkrimit.

2 Beci, Bahri: Janet Byron, "Për Historinë e formimit të Shqipes Standarde”, Studimet Albanistike në Amerikë, 2015.

3 Shkurtaj, Gjovalin: Sociolinguistikë e shqipes: Nga dialektologjia te etnografia e të folurit, f. 152 . 
Vepra është e organizuar në nëntë kapituj, në të cilët, ajo bën një kombinim të çështjes gjuhësore me faktorët socialë e politikë të kohës që çuan në kristalizimin e standardit të shqipes. Në monografi ajo mundohet të ndalet e të analizojë këtë çështje në fushën fonetike, morfologjike dhe leksikore, por siç sqaron dhe vetë, nuk trajton atë sintaksore. Përpos problemit të planifikimit gjuhësor në të cilën përqendrohet më së shumti vëmendja, çështja e politikës gjuhësore për J. Byron ka një rëndësi të veçantë në rastin e shqipes, ku roli dhe ndikimi i pushtetit ishte shumë i madh. Këtë e argumenton dhe me paraqitjen e një harte të origjinës së drejtuesve kryesorë komunistë (27 të tillë).

Nga ana tjetër, vjen vepra e Arshi Pipës, "Politika e gjuhës në Shqipërinë socialiste" ", botuar më 1989 në anglisht dhe përkthyer në vitin 2010 në variantin gegërisht dhe toskërisht. Ajo trajton gjerësisht problemin mbi t’ashtuquejtunën "Gjuhë të njësuar". Pipa e ka trajtuar në disa shkrime si para dhe pas regjimit këtë problem, por në këtë monografi e ka fokusin në faktorët mbizotërues politikë që u bënë përcaktues të një gjuhe sipas tij të shtërzuar.

“Gjuha e njësuar' nuk është as e njësueme, as e përbashkët, as kombëtare; ajo është një variante toskënishte e arnueme me disa huazime fonetike nga gegënishtja letrare, të cilat i mungojshin strukturës së toskënishtes”.

Punimi është i organizuar në 11 kapituj, të cilët paraprihen nga ajo që emërtohet nga autori si "Prolegomena", ku jepet përshkrimi shkurtimisht i traditës letrare gege e toske, njësimi i alfabetit në Kongresin e Manastirit, platforma e afrimit të dy dialekteve në Komisinë e Shkodrës. Mandej shfaqen dhe mendime rreth situatës politike të pasluftës, roli drejtues i A. Kostallarit në procesin e shqipes së njësuar letrare, që do të mbizotërojnë në monografi dhe që përbëjnë qëllimin e punimit. Përgjatë kapitujve të parë shihen ndryshimet mes dialekteve, elementet gege në gramatikën e standardit, spastrimi i leksikut dhe i frazeologjisë gege, apo në shumë raste, siç e quan ai, shfrytëzim të tyre në dobi të standardit. Punimin e pasuron me statistika dhe vëzhgime mbi tre fjalorët bazë të shqipes, atë të Kristoforidhit, Kostaq Cipos dhe me fjalorin e 1980-ës, të një grupi gjuhëtarësh të udhëhequr nga Androkli Kostallari.

Tek flet për historinë e shqipes standarde, para dhe pas 1944, përpos rrethanave dhe zhvillimeve specifike që i takojnë secilës prej këtyre periudhave, J.Byron, i sheh si të lidhura ngushtë me situatën politike të Shqipërisë. Për të, sikurse dhe për Pipën, arritja më e madhe sa i takon gjuhës shqipe në periudhën parasocialiste, ishte Kongresi i Manastirit, më 1908, ku iu kushtua vëmendje

4 Pipa, Arshi. Politika e gjuhës në Shqipërinë Socialiste, Tiranë, "Princi”, 2010. 


\section{Albanon}

\section{Revistë kulturore}

kryesore unifikimit të alfabetit, por jo çështjes së krijimit të një gjuhe të njësuar. Komisia letrare në Shkodër, do të ishte ajo që do të vendoste në fokus debatin për një gjuhë të përbashkët, duke arritur në konkluzionin se baza e saj duhet të afrohej me të folmen e Elbasanit. Që pas vitit 1923, ku nisi të përdorej si gjuhë zyrtare, pati një zgjerim të përdorimit të saj në administrata dhe arsim, me premisën sipas J.Byron-it, për t'u konsoliduar si një gjuhë standarde, por këtë drejtim e ndërpreu dhe e ndërroi qeveria e re socialiste. Në këtë mënyrë, për J.Byron, fakti që elbasanishtja nuk arriti të qëndronte gjatë në përdorim si një alternativë për të qenë standardi i gjuhës shqipe, nuk lidhet me faktorë të normave apo funksioneve gjuhësore, më shumë se sa ç'lidhet drejtpërdrejt me faktorë jashtëgjuhësorë, pra politikë. Për autoren, Shqipëria Socialiste, jo vetëm që nuk shfaqi interes rreth të folmes së Elbasanit, por duket se qëndrimi zyrtar për të qe negativ, duke çuar si rrjedhojë ndërprerjen e përdorimit të saj si një mjet shkrimi.

A.Pipa, rreth përpjekjeve të para për procesin e standardizimit të gjuhës shqipe në periudhën para luftës, përmend sigurisht mbledhjen e Komisisë së Shkodrës, duke theksuar dhe faktin e pjesëmarrësve apo drejtuesve kryesorë që ishin me origjinë gege, si: Pekmezi, Gurakuqi, Xhuvani. Përzgjedhja dhe përcaktimi prej tyre për standardin e shqipes, alternativën e dialektit të Elbasanit, sërish shihet prej Pipës si tendencioz dhe jo normativ. Komisia, përcaktoi, thotë Pipa, tiparet e të dy dialekteve, duke vendosur edhe rregullat ortografike për të dyja. Pasoja konkrete e këtij hapi të parë drejt standardizimit qe, jo standardizimi i gjuhës letrare shqipe, por fillimi i standardizimit të gegërishtes letrare, që për autorin nuk është as gegërishtja që flitet në Shkodër, as ajo që flitet në Elbasan apo Tiranë, por diçka e ndërmjetme që përfshin tiparet e toskërishtes, si p.sh. përdorimin e zanores $\ddot{e}$ që nuk përdoret në fund të fjalës në gegërisht.

Sakaq, sa i takon periudhës pas 1944, është e kuptueshme se çdo zhvillim që ndodhi me çështjen e gjuhës shqipe, studiuesja e lidh kryesisht, për të mos thënë plotësisht, me faktorët politikë të kohës, për të cilën mori dhe kundërpërgjigje nga A. Kostallari. Toskërishtja do të përzgjidhej si baza e shqipes standarde, përzgjedhje që erdhi për shkak të udhëheqësve politikë të kohës.

"Përzgjedhja, erdhi për shkak të faktorëve politikë: shumica e udhëheqësve të Lëvizjes Nacionalçlirimtare ishin nga Jugu dhe dokumentet ishin shkruar kryesisht në toskërishte. Kur udhëheqësit e kësaj lëvizjeje erdhën në pushtet, i diktuan vendit dialektin e tyre duke e kthyer në normë kombëtare.".

5 Byron, Janet, Përzgjedhje midis alternativash në standardizimin e gjuhës dhe shkrime të tjera, Tiranë, 2012. Të gjitha citimet i referohen këtij botimi. 
NëShqipëri, udhëheqja politike që fliste toskërisht ia imponoi popullsisë dialektin e saj duke e vënë në themel të shqipes standarde.

Shumica e njerëzve që ishin pjesë e hierarkisë komuniste dhe që krijuan shtetin autonom në Shqipëri nëpërmjet betejave partizane, ishin nga Jugu. Kjo udhëheqje, kryesisht jugore, promovoi toskërishten si bazë të standardit të shqipes.

Njëjtë sikur J. Byron, edhe A. Pipa, çështjen e përcaktimit të standardit të gjuhës shqipe e lidh drejtpërdrejt me situatën politike të pas viteve 1944. Argumentin e tij se radha politike u bë përcaktuese, e plotëson me fakte e statistika prej një studimi të Petër Priftit, i cili jep me numra konkretë përpjesëtimin mes gegëve dhe toskëve pjesëmarrës ne byronë politike në përgjithësi, por dhe në Kongresin e Drejtshkrimit ku dhe u realizua zyrtarisht standardi gjuhës.

Peter Prifti ká përpilue nji statistikë të përbâmjes së Politbyrosë prej 1948 deri me 1976 ("Socialist Albania since 1944", 1978, f. 50-51). Tue gjykue prej êmnavet, në Kongresin e Parë të Partisë (1948) përpjestimi mes toskëvet dhe gegëvet ishte 7 me 2; në Kongresin e Dytë (1952) 9 me 1; në Kongresin e Tretë (1956) 13 me 3; në Kongresin e Katërt (1961) 13 me 2, në Kongresin e Pestë (1966) 13 me 3, në Kongresin e Gjashtë (1971) 13 me 4; dhe në Kongresin e Shtatë (1976) 15 me 2. Në Kongresin e Tetë (1981) përpjestimi u përmirësue për gegët: 14? me 4?. Shkurt, toskët kanë stërsundue në Byronë Politike gjatë gjithë historisë së Partisë. Në 1972, kúr u mblodh Kongresi i Drejtshkrimit, në Byronë Politike kishte 13 toskë dhe 4 gegë. Përpjestimi që del nga përbâmja e redaktorëve të Fjalorit të gjuhës së sotme shqipe âsht 4 me 1. Hegemonia politike toske pasqyrohet në hegemoninë kulturore të toskënishtes në lámën e gjuhësisë. Koincidencë e vetëm aqë? Prej shumës së 28 antarëvet të Politbyrosë gjatë periudhës 1948-1976, 21 kanë qênë toskë dhe 7 gegë. Gjatë po kësaj periudhe janë spastrue ose rrëzue 7 toskë, domethânë nji e treta e shumës, dhe 5 gegë, domethânë gati të gjithë me përjashtimin e dy anëtarëve.

Pipa analizon faktin se, ndonëse thuhej se gjuha e njësuar duhej arritur jo si e imponuar me dekret (duke ju referuar këtu citimit të marrë nga vepra e Enver Hoxhës), kjo ishte e pavërtetë. Kjo, pasi çdo mendim i ndryshëm nuk pranohej, duke dhënë si shembull rastin e Tuk Jakovës, i cili, kërkonte apo shtronte tezën e ruajtjes së gegërishtes letrare dhe kundërshtonte rrafshimin e gjuhës. Megjithatë, Pipa beson se e gjitha çka u vendos më 1972 ishte një fasadë dhe thjeshtë vulosi një fakt të kryer, pasi çdo gjë ishte zbatuar vetvetiu nga nëntori i 1944 e deri më 1972. 


\section{Albanon}

\section{Revistë kulturore}

Asht e vërtetë se imponimi nuk u-bâ me ngut, dhe se prej nandorit të 1944-s deri te vendimi i Kongresit të Drejtshkrimit (1972) rrodhën mâ se njizet vjet. Por gjatë këtyne dý dekadave, tanksi i rrafshimit vazhdoi punën e vet. Kështû që, kur u mblodh Kongresi i Drejtshkrimit, ky veç vulosi nji "fait accompli".

Të dy autorët e marrë në shqyrtim, por më së shumti Pipa, thekson se ajo çka ndodhi shkaktoi një diskriminim të hapur ndaj gegëve. J.Byron, po ashtu jep argumentin se zonat ku flitet gegërishtja ishin katolike e si rrjedhojë të diskretituara.

Argumentet gjuhësore të dhëna rreth viteve '60-'70, por dhe më pas, theksonin faktin se baza e standardit të shqipes nuk ishte toskërishtja, por një përzierje e të dy dialekteve pa qenë mbizotërues asnjëri prej tyre.

Në një artikull kushtuar gjuhës letrare shqipe, A.Kostallari flet për mendimin e shprehur nga ballkanologë të ndryshëm, sipas të cilëve, gjuha shqipe e arriti njësimin përmes një procesi të ndërlikuar të theksimit të elementeve integruese dhe konverguese.

Përpos tyre, Kostallari përmend disa gjuhëtarë, që sipas tij, kanë nënvlerësuar rolin e kësaj konvergjence dhe kanë absolutizuar peshën specifike të disa tipareve të strukturës fonetike. Kjo ka bërë që, të interpretohet se shqipja e sotme letrare, është njësuar thjesht si një toskërishte letrare e ngritur drejtpërdrejt në gjuhë letrare kombëtare.

Ky interpretim i gabuar e ka burimin edhe te mosshkëputja e ndonjë studiuesi nga teoritë që e kërkojnë zgjidhjen e problemit të gjuhës letrare kombëtare, vetëm te një bazë e ngushtë njëdialektore, duke e parë procesin e njësimit si një kalim të thjeshtë nga një sistem shumëqendror (policentrik), dy a më shumë variantesh, në një sistem njëqendror (monocentrik), d.m.th. në sublimimin e drejtpërdrejtë vetëm të një varianti letrar e në uljen e prestigjit a në zhdukjen pa gjurmë të varianteve të tjera. ${ }^{6}$

Duke përmendur këto gjuhëtarë me konceptime të gabuara sipas tij, rreth çështjes së standardit të shqipes i referohet dhe drejtpërdrejt veprës "Përzgjedhje midis alternativash në standardizimin e gjuhës: rasti $i$ shqipes" të Janet Byron, që për Kostallarin, është një vepër me pohime kundërthënëse dhe se njësimi i shqipes letrare trajtohet në mënyrë të shtrembëruar e të thjeshtëzuar. Kostallari mohon kategorikisht se toskërishtja pas 1944-ës të jetë vendosur në mënyrë horizontale si një gjuhë standarde e që pas këtij

6 Kostallari, Androkli. Gjuha letrare kombëtare shqipe dhe epoka jonë: materiale të Konferences shkencore mbajtur në Tiranë, më 7- 8 dhjetor 1984. 
veprimi të ketë nisur marrëdhëniet me gegërishten letrare dhe me të folmet popullore të Veriut. Thjeshtëzimi i këtij procesi, shprehet Kostallari, arrin deri aty sa pohohet se zhdukja e dialekteve ka marrë bekimin zyrtar, duke cituar këtu nga vepra e J. Byron. Mirëpo, ai shprehet se politika gjuhësore e kohës ka pasqyruar vetëm zhvillimin objektiv, duke mos u nisur nga pozita e vetëm një dialekti apo të një krahine.

"Studimet në fushën e gjuhës letrare shqipe, të cilat vijojnë të thellohen, kanë vërtetuar tashmë se variantet letrare shqipe të së kaluarës, qü nga gjysma e dytë e shekullit XIX kanë ndërvepruar gjithnjë e më shumë njëri me tjetrin dhe kanë ushtruar pandërprerë ndikime të ndërsjella”. Në punimin e tij për të argumentuar të kundërtën e asaj çka mendohej rreth faktit se standardi i shqipes ka në bazë toskërishten letrare, Kostallari paraqet një skemë ku gjuha shqipe, shfaqet si sistem sistemesh dhe standardi apo Gjuha Letrare Kombëtare, siç e emërton ai, shfaqet si sistem mbidialektor. Në skicë, shihet se theksohen elementet e përbashkëta të dy dialekteve si dhe ato elemente të veçanta të dy dialekteve.

\section{GJUHA SHQIPE SI SISTEM SISTEMESH DHE GJUHA LETRARE KOMBËTARE SI SISTEM MBIDIALEKTOR}

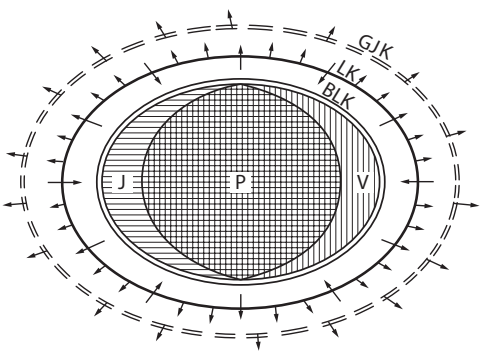

$\mathrm{P} \quad=$ Elementet e përbashkëta të të dy dialekteve

$\mathrm{J} \quad=$ Elementet e veçanta të dialektit të jugut

$\mathrm{V}=$ Elementet e veçanta të dialektit të veriut

BLK = Baza e gjuhës letrare kombëtare

$\mathrm{LK}=$ Gjuha letrare kombëtare

GJK = Gjuha kombëtare

Megjithatë rreth kësaj çështje të bashkëveprimit të dialekteve mes tyre, J.Byron dhe A.Pipa, në mënyrën e tyre, këmbëngulin se në fakt kemi të bëjmë me dominancën e një dialekti mbi tjetrin. A.Pipa e shpreh se gati kemi të bëjmë me një rast tjetër ekstrem, përpos të qenit vendi i vetëm në botë ateist, ku një pjesë e popullatës pushton një pjesë tjetër duke i imponuar dhe dialektin e vet. Kjo, sipas tij, ishte një lloj politike gjuhësore staliniste, që mbolli farën e urrejtjes.

J.Byron, nga ana tjetër, thotë se gjuha standarde pranoi vetëm veçoritë e toskërishtes, ndërsa veçoritë e gegërishtes nuk janë pranuar. Sipas saj, para vitit 1944, dialektet e gegërishtes dhe toskërishtes kishin lidhje me gegërishten letrare dhe toskërishten letrare, ndërsa pas ' 44 e zyrtarisht në 


\section{Albanon}

\section{Revistë kulturore}

'72, shqipja standarde duhet quajtur më mirë toskërishtja standarde dhe, jep edhe skemën e mëposhtme.

Marrëdhëniet para vitit 1944

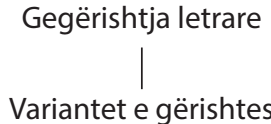

Marrëdhëniet pas vitit 1944
Toskërishtja letrare

Variantet e toskërishtes

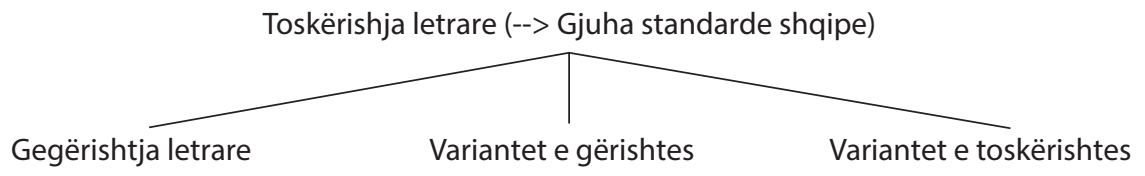

Në veprat që po analizojmë, autorët priren të shohin dhe ato elementë të gegërishtes që janë përfshirë në standardin e shqipes, por të dy janë të mendimit se kemi të bëjmë më së shumti me elemente që toskërishtja ka marrë prej gegërishtes se sa ç'mund të thuhet se janë përdorur si elemente për standardin. Kështu, J. Byron, shprehet se kemi të bëjmë me "buazime të gegërishtes në toskërishte, të cilat e pasurojnë kodin marrës, por nuk e shtrembërojnë a gjymtojnë atë". Ajo sheh prezencën në standard të disa elementeve gege, si p.sh:

- prania e disa elementeve leksikore,

- përemri "i vet",

- diftongu ue në disa grupe të caktuara fjalësh.

Dy trajta të gegërishtes:

- Mbaresen e pjesores në -ues për "nomina agentis”, si: mësues, sulmues;

- Mbaresën -ueshëm për adjektiva si: i kuptueshëm, i besueshëm;

- Standardi po ashtu ka adaptuar nga gegërishtja karakteristikën e bashkëtingëlloreve të zëshme në fund të fjalës: elb/ elp, u dogj/ u doq.

Pipa, nga ana tjetër, shkon dhe më tej e tregohet edhe më i ashpër sa i takon kësaj çështje, duke iu referuar kësaj, jo vetëm si një nevojë e toskërishtes për këto elemente gege, por dhe raste të toskëzimit të leksikut dhe frazeologjisë gege. Për Pipën janë pranuar fjalë të gegërishtes, për të pasuruar fjalorin në dobi të toskërishtes në këtë rast, më shumë se sa në dobi të standardit, pasi 
këto janë shfrytëzuar e tjetërsuar nga një dialekt për përfitim të dialektit tjetër. Pra, sipas tij, ky njësim është përvetësim, plaçkitje, apo kolonizim gjuhësor krahinor.

Në përfundim, mund të themi se veprat e dy autorëve bashkohen në faktin se politika e kohës ndikoi në mënyrë vendimtare në ndryshimin e rrjedhës së mëparshme në fushë të standardizimit dhe se standardi i përcaktuar nuk ishte gjë tjetër, veçse ngritje dhe vazhdim i toskërishtes letrare. Nuk mund të mohohet roli dominant i politikës për të cilën argumentojnë gjatë në monografitë e tyre këta autorë, megjithatë, duhet theksuar dhe vlerësuar edhe roli i jetës kulturore, e mbi të gjitha, asaj letrare, në periudhën e Rilindjes Kombëtare. Në gjykimin tonë duhet parë më gjatë siç përmendem më lart roli i Rilindjes Kombëtare, gjatë së cilës, duke nisur nga gjysma e dytë e shekullit XIX dhe fillimi i shekullit XX, toskërishtja u lëvrua shumë në shkrime. Gjatë kësaj periudhe dolën një numër i madh gazetash, librash shkollorë, tekstesh letrare në toskërisht. Mund të përmenden po ashtu, një numër i madh i rilindasve që ishin toskë, e shkrimet e tyre bënë që toskërishtja të lëvrohej aq sa gati krijoi një varietet letrar. Mund të përmendim si një shembull konkret meritën që pati në këtë aspekt revista "Albania" e Konicës, përgjatë viteve 1897-1909. Pra, përpos ndikimit të pushtetit, që historia njeh raste të shumta se si përmes mjeteve politike i është dhënë fund policentrizmit gjuhësor, duhet vlerësuar dhe parë ndoshta si primare, kontributi dhe lëvrimi i gjuhës në periudhën e Rilindjes (Renaissance), siç kjo e fundit ka qenë shpeshherë përcaktuese në shumë gjuhë të tjera në procesin e tyre të standardizimit.

\section{Bibliografi}

Byron, Janet: "Përzgjedhje midis alternativash në standardizimin e gjuhës dhe shkrime të tjera," Tiranë, 2012.

Pipa, Arshi: "Politika e gjuhës në Shqipërinë Socialiste”, Tiranë, Princi, 2010.

Kostallari, Androkli: "Gjuha letrare kombëtare shqipe dhe epoka jonë": materiale të Konferences shkencore mbajtur në Tiranë, më 7- 8 dhjetor, 1984.

Holmes, Janet: “Hyrje në Sociolinguistikë”, Botime Pegi, Tiranë 2015.

Beci, Bahri: "Janet Byron për historinë e shqipes standarde", Studimet Albanistike në Amerikë, 2015.

Shkurtaj, Gjovalin: "Sociolinguistikë e shqipes: Nga dialektologiia te etnografia e të folurit". 